\title{
Prevalence and Antimicrobial Susceptibility Pattern of Asymptomatic Urinary Tract Infections of Bacterial and Parasitic Origins among University Students in Redemption Camp, Ogun State, Nigeria
}

\author{
F. Ayoade ${ }^{1^{*}}$, D. D. Moro ${ }^{2}$, O. L. Ebene ${ }^{1}$ \\ ${ }^{1}$ Department of Biological Sciences, College of Natural Sciences, Redeemer's University, \\ Redemption City, Nigeria \\ ${ }^{2}$ Department of Microbiology, Lagos State University, Lagos, Nigeria \\ Email: *fayoade22@gmail.com
}

Received July 25, 2013; revised August 26, 2013; accepted September 2, 2013

Copyright (C) 2013 F. Ayoade et al. This is an open access article distributed under the Creative Commons Attribution License, which permits unrestricted use, distribution, and reproduction in any medium, provided the original work is properly cited. In accordance of the Creative Commons Attribution License all Copyrights (C) 2013 are reserved for SCIRP and the owner of the intellectual property F. Ayoade et al.. All Copyright (C 2013 are guarded by low and by SCIRP as a guardian.

\begin{abstract}
Asymptomatic urinary tract infections (UTIs) of bacterial and parasitic origins occur in both males and females where bacteria and/or parasites are present in the urine, with the absence of clinical signs or symptoms in the host. Using microbiological methods, mid-stream urine collected from sixty (60) Redeemer's University students comprising apparently healthy 30 male and 30 female undergraduate students were examined. The samples were cultured on CLED and MacConkey agar. Bacteriuria was observed in 15 (25\%) of the samples while there was no significant growth in 34 (56.7\%), and no growth in 11 (18.3\%). Prevalence of significant bacteriuria was higher in females 11 (73.3\%) than males 4 (26.7\%). The bacteria isolated were Staphylococcus aureus, Escherichia coli, Pseudomonas aeruginosa, Streptococcus spp, and Klebsiella spp. The isolates were resistant to amoxycillin, augumentin and cotrimoxazole but most were highly susceptible to ofloxacin. Schistosoma haematobium and Trichomonas vaginalis were the two asymptomatic UTI-causing parasites isolated from the samples used in this study. Out of the 30 males examined using the microscopy method, 1 (1.67\%) had $T$. vaginalis while the females had higher prevalence of 2 (3.33\%) out of 30 females examined. Out of the overall participants examined for S. haematobium eggs, 15 (25\%) had Schistosomiasis in which the males had higher prevalence of 10 (33.33\%) while the females had 5 (16.67\%). These results are lower than those observed in similar rural communities in Nigeria possibly due to effective health education, availability of potable water, higher-than average income and hygienic practices on Redemption Camp, Ogun State, Nigeria.
\end{abstract}

Keywords: Asymptomatic UTI; Urinary Tract Infections; Antimicrobial Resistance

\section{Introduction}

Urinary tract infections (UTI) represent one of the most common diseases encountered in medical practice today and occurring from the neonate to the geriatric age group [1]. Despite the widespread availability of antibiotics, UTI remains the most common bacterial infection in the human population [2]. 150 million individuals have been reported to be affected by UTIs annually worldwide [3]. Urinary tract infections occur as a result of the microbial

\footnotetext{
"Corresponding author.
}

colonization of urine and the invasion of any structure of the urinary tract by microbial organisms such as bacteria, viruses, yeasts and parasites [4].

The resulting disease conditions from UTI include cystitis and pyelonephritis which is known to be non-age discriminatory as it affects both older persons and infants. Moreover, pyuria as evidenced by the inflammation of the genitourinary tract is common in subjects with asymptomatic bacteriuria [5]. Asymptomatic UTI in particular has been associated with an increased risk of developing pyelonephritis, maternal and infant morbidity, pre-term labour and low birth weight [6]. UTIs of both 
bacterial and parasitic origins have been associated with high incidence of squamous cell carcinoma of the bladder and the cervix [7]; Escherichia coli and Schistosoma spp. are the most widely reported UTI-causing bacteria and parasite respectively [8].

Microbial invasion being the basis of urinary tract infection could be seen in various clinical manifestations resulting in various disease conditions in both males and females of all ages. Young adults particularly females are, however, the most at risk of bacteriuria. For example, in the United States, UTIs result in approximately 8 million physician visits and more than 100,000 hospital admissions per year of sexually active women treated annually for UTIs. Up to $95 \%$ of the UTI cases in the U.S are treated with antibiotics such as cotrimoxazole without bacteriological investigation since these infections are so routinely encountered in medical practice [9], [10]. This kind of indiscriminate use of antibiotics is, however, fraught with the problem of pathogen resistance to antibiotics.

Asymptomatic UTIs occur when urinary tract pathogens enter into the bladder without causing apparent symptoms. Typically the pathogens are usually eliminated by host defense factors when they persist only for a short time in the human host, however when such pathogens stay in the urinary system for a long time, symptomatic urinary tract infections result [8,11]. Asymptomatic parasitic infections are endemic in Nigeria and are usually neglected until infections become symptomatic with adverse effects particularly in immune-stressed individuals infected with secondary urinary tract pathogens. Escherichia coli and Schistosoma spp. are the most commonly reported bacteria and parasites associated with UTIs in the country, especially southwest Nigeria [8].

The presence of bacteria in urine is known as bacteriuria. Asymptomatic bacteriuria is a urinary tract infection that occurs in both males and females where bacteria are present in urine with the absence of clinical signs or symptoms in the host [12]. Asymptomatic bacteriuria is defined by the presence of at least $10^{5}$ colony forming units (CFU) of organism per millilitre in cultures of urine specimens in the absence of symptoms of infection referable to the urinary tract [13]. Early detection of bacteriuria is expected to aid the detection of correctable abnormalities of the urinary tract and the prevention of renal scarring obstructive atrophy, hypertension and renal insufficiency among other serious health maladies that may develop as a direct result of asymptomatic urinary tract infection. Moreover, treatment is more effective when the culprit organism is correctly identified as indiscriminate treatment with antibiotics is known to result in microbial resistance to antibiotics. Apart from E. coli other bacteria implicated in causing bacteriuria includes Pseudomonas aeruginosa, Staphylococcus aureus, Klebsiella spp., and Streptococcus spp. [14].

Ibadan, the largest city in Southwestern Nigeria [11] reported a $57.5 \%$ prevalence rate of Urinary schistosomiasis with over $75 \%$ of infected school pupils exhibiting concomitant bacteriuria. The results show a linear relationship between contact and usage of stream water and increase in rate of infection; bacteriuria seems most often to occur concurrently with parasitic urinary tract infections. Other parasites apart from Schistosoma spp. (particularly S. hematobium) that have been implicated in UTIs include Wacheria bancrofti, Enterobius vermicularis and Onchocerca volvulus $[15,16]$.

The risk factors identified with high prevalence of UTIs in young adult females include sexual intercourse, spermicide-based contraception, and a history of UTIs [9]. Redemption Camp, a fast-growing Christian community, is located in Ogun State, western Nigeria. Redemption Camp, a suburb of the commercial capital city Lagos, is populated by mostly educated individuals of medium to higher income earning capacity. A population of young adults as those of Redeemer's University undergraduate students aged 15 - 30 is hence a good target to indicate the prevalence of UTIs in a rural community such as Redemption Camp, since this age group represents the age group with the highest prevalence for UTIs. Prevalence of UTIs is also known to be higher among individuals in lower socioeconomic classes and those with lower educational status [17].

The present work reports the relationships between educational and economic status and UTI prevalence. In nearby Sagamu, for example, [19] reported a prevalence rate of $23.9 \%$ while [14] reported a prevalence rate of $86.6 \%$ in Benin City, Nigeria. A prevalence rate of $7 \%$ in pregnant women has been reported in Ethiopia [18] while in Canada the prevalence rate varies from 4\% - 7\% [17].

The rate of bacterial resistance to antimicrobial agents is on the increase in many countries [20]. The rate of bacterial resistance to antimicrobial agents in the management of UTIs is particularly higher in Nigeria due to a high prevalence of fake and substandard drugs [21,22]. The present study therefore seeks to determine the prevalence rate of asymptomatic UTIs on Redemption Camp using the Redeemer's University students as a case study. The UTI-causing microbial agents were isolated, identified and characterized. The degree of susceptibility of the pathogens to the commonly used antibiotics by physicians on Redemption Camp was also studied and the result is expected to provide useful information to assist physicians on Redemption Camp and surrounding areas towards developing a better management of urinary tract infections through good prescribing habits. 


\section{Materials and Methods}

\subsection{Collection of Samples}

Mid-stream urine was collected from apparently healthy undergraduates of Redeemer's University, (30 males and 30 females). The samples were collected into sterile plastic disposable bottles, refrigerated and examined within 2 - 4 hours of collection. The University student population is well known to be a high risk segment of the community due to age sex, sexual activities among other predisposing factors $[9,11]$. All the students were apparently healthy and symptoms free at the time samples were collected. Students on antibiotic treatment within one week of the study were avoided.

\subsection{Bacteriology}

Samples were examined using standard methods [16]. A 30 morse gauge, $3.26 \mathrm{~mm}$ calibrated wire loop capable of delivering $0.001 \mathrm{ml}$ of urine was used for culturing on Cysteine-Lactose Electrolyte Deficient (CLED) and MacConkey agar. The culture plates were incubated aerobically at $37^{\circ} \mathrm{C}$ for 24 hours. Culture plates without visible growth were further incubated for an additional 24 hours before being discarded. The number and types of colonies grown on the medium (CLED) was recorded as being insignificant when samples gave a colony count of less than $10^{4} \mathrm{CFU}$ ml. Samples with colony count equal to or greater than approximately $10^{5} \mathrm{CFU} \mathrm{ml}$ of the urine samples were considered to have significant bacteriuria. Bacterial isolates were identified based on a combination of cultural, morphological and biochemical characteristics as described by [23].

\subsection{Parasitological Analysis}

$10 \mathrm{ml}$ of urine sample was poured aseptically into a centrifuge tube and spun in the centrifuge (Model: J.P Selecta, s.a.Centro-8) at $500-1000$ rpm for 5 minutes. The supernatant was decanted leaving the sediment at the bottom of the tube. A drop of the sediment was pipetted and placed on a microscope slide, then covered with a cover slip. The deposit was examined using $\times 40$ objective of the microscope watching for eggs of $S$. hematobium and Trichomonas vaginalis while the characteristic crystals found in the urine samples depending on the culprit parasite(s) was noted using the methods described by [16]. The pipette was rinsed several times with distilled water after the sediments from each urine sample was placed on the slide to avoid contamination and placed in canister for sterilization. Student t-test analysis was used to determine the significant difference in prevalence of infection between males and females examined in this study.

\subsection{Antimicrobial Susceptibility Testing}

Antibiotic susceptibility testing of the isolated test organisms, namely Escherichia coli, Staphylococcus aureus, Klebsiella aerogenes and Pseudomonas aeruginosa was carried out using the following antibiotics: Amoxycillin (25 mg) Gentamycin (10 mg), Nalidixic acid (30 $\mathrm{mg})$, Augmentin (30 mg), Erythromycin (5 mg), Tetracyclin (25 mg), Nitrofurantoin (200 mg), Cloxacillin (5 mg), Cotrimoxazole (25 mg), Chloraphenicol (30 mg), Notrofurantoin (30 mg), Cifloxacin, Tarivia, and ciprofloxacin (5 mg).

The nutrient broth was prepared according to the manufacturer's specification and $10 \mathrm{ml}$ was dispensed into sterile test tubes. A sterile loop was used to pick a pure colony of the test isolate and emulsified in the nutrient agar. The nutrient agar was then incubated at $37^{\circ} \mathrm{C}$ for 18 - 24 hours.

Normal saline was prepared using sodium chloride and distilled water and the normal saline was sterilized using the autoclave for 15 minutes at $121^{\circ} \mathrm{C}$ then allowed to cool. Then the test organism was placed in $10 \mathrm{ml}$ of the normal saline in a test tube then incubated for 2 hours. Turbidity standard was used Mc Farland 0.5, this is barium sulphate standard against which the turbidity of the test and control inocula was compared, when matched with the standard the inocula gives almost confluent growth [24].

A sterile swab was used to inoculate the Mueller Hinton agar previously prepared by putting the sterile swab into the inocula and rotating the swab against the side of the test tube above the level of the suspension. The swab was used to streak the surface of the Mueller Hinton Agar plates in three directions, rotating the plates in approximately $60^{\circ} \mathrm{C}$ to ensure even distribution with a sterile forceps. The approximate antimicrobial sterile discs were placed evenly distributed on the inoculated plates. The plates were inverted and incubated aerobically at $37^{\circ} \mathrm{C}$ and examined after $18-24$ hours incubation and from the underside of the plates. A ruler was used to measure the diameter of the zone of inhibition in millimetres. The reaction of the test organism to each antibiotic was reported as sensitive, intermediate or resistant on the basis of zone of inhibition [16].

\section{Results}

Of the sixty (60) samples examined 15 (25\%) showed significant bacteriuria, 34 (56.7\%) had insignificant bacteriuria while $11(18.3 \%)$ had no growth (Table 1). Table 2 summarizes the age and sex distribution of individuals from whom urine samples were obtained. The data reveals that 15 subjects out of a total of 60 individuals had significant bacteriuria, with 12 (80.0\%) out of the 15 individuals found in the 21 - 30 age group. Table 2 
also shows that significant bacteriuria was found in a total of 15 (80\%) individuals, with 3 (20\%) of them from the 11 - 20 age group.

Table 3 shows that out of the 15 subjects with significant asymptomatic bacteriuria, Escherichia coli remains the most frequently occurring culprit accounting for 6 (40\%) of the infections followed by 4 (26.7\%) recorded for Pseudomonas spp.; 2 (13.3\%) of the subjects had Staphylococcus aureus, 2 (13.3\%) had Klebsiella species and $1(6.7 \%)$ had Streptococcus spp.. Of the 15 subjects with bacteriuria, 4 (26.7\%) were males and 11 (73.3\%) were females.

Parasitological examination of urine samples from the subjects identified two UTI-causing parasites viz., Schistosoma haematobium and Trichomonias spp. The results showed that 15 (25\%) subjects were infected with Schistosoma haematobium; with males having prevalence rate of 10 (33.33\%) and females 5 (16.67\%). Chi-square analysis confirms a significant association between infection and sex $(p<0.05)$. It was observed, that students within the age range of 11 - 20 years constituted of the 8.33\% infected while those between 21 - 30 years constituted $16.67 \%$ of subject with Schistosomiasis (Table 4). On the other hand, 3 (5\%) of 60 subjects examined were infected with Trichomoniasis, with males having a prevalence rate of 1 (1.67\%) and females 2 (3.33\%) as shown in Table 5. Chi-square analysis confirmed a significant association between infection and sex $(p<0.05)$ with results showing that infection is more prevalent among the females than the males. Moreover, the prevalence of Trichomoniasis was 2 (3.33\%) amongst the age group of between 21 - 30 years; no Trichomoniasis was found amongst the aged between 11 - 20 years (Table 5).

The antibiotics used during the course of study were multiple disc positive and negative disc, which included; Amoxycillin, erythromycin, tetracycline, cloxacillin, gentamicin, cotrimoxazole and chloraphenicol while the negative discs were amoxicillin, cotrimoxazole, nitrofurantoin, gentamycin, nalidixic acid, ofloxacin and nitrofurantoin. All the isolates were resistant to amoxycillin, augumentin and cotrimoxazole but most of the isolates were assessed to be highly susceptible to ofloxacin. It was observed that Staphylococcus aureus was particularly resistant to most of the antibiotics used but showed a considerable level of susceptibility to gentamycin, cotrimoxazole and chloraphenicol. Three antibiotics namely ofloxacin, gentamycin and nitrofurantoin were found to be most effective for gram negative bacteria while

Table 1. Number of urine samples obtained from the study population.

\begin{tabular}{ccc}
\hline & Number of occurrence & Percentage (\%) occurrence \\
\hline Positive samples (with significant bacteriuria) & 15 & 25 \\
Negative samples (samples no significant bacteriuria) & 34 & 56.7 \\
Number of samples with no growth & 11 & 18.3 \\
Total & 60 & 100 \\
\hline
\end{tabular}

Table 2. A summary of the age and sex distribution of students used for the study.

\begin{tabular}{ccccc}
\hline Age distribution & No. of Males Examined & No. of Females Examined & $\begin{array}{c}\text { Frequency of Individuals } \\
\text { by Age-group }\end{array}$ & $\begin{array}{c}\text { Frequency of individuals } \\
\text { with significant bacteriuria }\end{array}$ \\
\hline $0-10$ & 0 & 0 & 6 & 12 \\
$11-20$ & 6 & 24 & 48 \\
$21-30$ & 30 & 30 & 60 \\
Total & 24 & 15 & 0 \\
\hline
\end{tabular}

Table 3. Bacteriuria-causing pathogens isolated from the students used in the study.

\begin{tabular}{ccccc}
\hline Pathogens isolated & No. of positive culture & No. of infected males & No. of infected females & Percentage of occurrence (\%) \\
\hline Escherichia coli & 6 & 2 & 2 & 40 \\
Pseudomonas aeruginosa & 4 & 0 & 2 & 2 \\
Klebsiella aerogenes & 2 & 0 & 1 & 13.3 \\
Staphylococcus aureus & 2 & 0 & $11(73.3 \%)$ \\
Streptococcus sp. & 1 & $4(26.7 \%)$ & 6.7 \\
\hline
\end{tabular}


Table 4. Prevalence of Schistosomiasis haematobium infection by sex and age in Redeemer’ University students.

\begin{tabular}{ccccc}
\hline Age & No. Examined in male & No. Infected in male & No. Examined in female & No. Infected in female (\%) \\
\hline $0-10$ & 0 & 0 & 0 & 0 \\
$11-20$ & 6 & $4(13.33 \%)$ & 7 & $3(10)$ \\
$21-30$ & 24 & $6(20 \%)$ & 23 & $2(6.67)$ \\
Total & 30 & $10(33.33 \%)$ & 30 & $5(16.67)$ \\
\hline
\end{tabular}

Table 5. Prevalence of Trichomoniasis infection by age and sex among Redeemer's university students.

\begin{tabular}{ccccc}
\hline Age (years) & No. Examined in male & No. Infected in male (\%) & No. Examined in female & No. Infected in female (\%) \\
\hline $0-10$ & 0 & 0 & 0 & 0 \\
$11-20$ & 5 & 0 & 6 & 2 \\
$21-30$ & 25 & 1 & 24 & 2 \\
Total & 30 & $1(1.67)$ & 30 & $2(3.33)$ \\
\hline
\end{tabular}

Table 6. (a) and (b) antibiotic susceptibility pattern (\%) of gram negative isolates.

(a)

\begin{tabular}{cccccccccc}
\hline No. of Isolates tested & Organism isolated & OFX & NAL & GEN & NIT & COT & AMX & TET & AUG \\
\hline \multirow{2}{*}{6} & E.coli & $\mathrm{S}$ & $\mathrm{R}$ & $\mathrm{S}$ & $\mathrm{S}$ & $\mathrm{R}$ & $\mathrm{R}$ & $\mathrm{S}$ & $\mathrm{R}$ \\
& & 0.0 & 100 & 0.0 & 0.0 & 100 & 100 & 0.0 & 10 \\
2 & Klebsiella aerogenes & $\mathrm{S}$ & $\mathrm{R}$ & $\mathrm{S}$ & $\mathrm{S}$ & $\mathrm{R}$ & $\mathrm{R}$ & $\mathrm{R}$ & $\mathrm{R}$ \\
& & 0.0 & 100 & 0.0 & 0.0 & 100 & 100 & 100 & 100 \\
& & $\mathrm{~S}$ & $\mathrm{~S}$ & $\mathrm{~S}$ & $\mathrm{R}$ & $\mathrm{R}$ & $\mathrm{R}$ & $\mathrm{I}$ & $\mathrm{R}$ \\
& Pseudomonas aureginosa & 0.0 & 0.0 & 0.0 & 100 & 100 & 100 & 100 & 100 \\
\hline
\end{tabular}

(b)

\begin{tabular}{cccccccccc}
\hline No.of Isolates tested & Organism isolated & AUG & AMX & ERY & TET & CXC & GEN & COT & CHL \\
\hline \multirow{2}{*}{2} & Staphylococcus aureus & $\mathrm{R}$ & $\mathrm{R}$ & $\mathrm{R}$ & $\mathrm{R}$ & $\mathrm{R}$ & $\mathrm{S}$ & $\mathrm{S}$ & $\mathrm{S}$ \\
& & 100 & 100 & 100 & 100 & 100 & 0.0 & 0.0 & 0.0 \\
& & $\mathrm{R}$ & $\mathrm{R}$ & $\mathrm{R}$ & $\mathrm{S}$ & $\mathrm{R}$ & $\mathrm{S}$ & $\mathrm{S}$ & $\mathrm{S}$ \\
\multirow{2}{*}{1} & Streptococcus spp & 100 & 100 & 100 & 0.0 & 100 & 0.0 & 0.0 & 0.0 \\
\hline
\end{tabular}

Key: S = Sensitive/susceptible, R = Resistance, I = Intermediate, AUG = Augumentin, AMX = Amoxycillin, ERY = Erythromycin, TET = Tetracycline, CXC = Cloxacillin, GEN = Gentamicin, COT = Cotrimoxazole, CHL = Chloraphenicol, OFX = Ofloxacin, NAL = Nalidixic acid, NIT = Notrofurantoin.

gentamycin, chloraphenicol and cotrimoxazole were effective for gram positive (Table 6(a) \& (b)). The antibiotic susceptibility pattern of the gram negative isolates and that of gram positive isolates are shown in Table 6(a) and (b) respectively.

\section{Discussion}

The prevalence of bacteriuria in the present study was $25 \%$. This value is similar to the prevalence of $23.9 \%$ reported for nearby Sagamu but quite low when compared to urbanized Nigerian cities of Ibadan, Lagos and Jos where prevalence of $57.5 \%$ [11], 38.6\% [25] and $35.5 \%$ [26] have been reported in those cities respectively. The prevalence of bacteriuria on Redemption
Camp is even lower when compared with smaller Nigerian towns as Lafia, Nasarawa State where prevalence as high as $60 \%$ have been reported [27]. The prevalence in Lafia is within range of the $77.9 \%$ prevalence recorded for prison inmates [28]. Such high prevalence percentages in suburban Nigeria have been ascribed to predisposing factors such as sexual intercourse, peer group influence, pregnancy and low social economic status $[25,29,30]$. Redemption Camp on the other hand though suburban has adequate infrastructures such as uninterrupted supply of pipe borne water and electricity, coupled with the fact that a vast majority population of this Christian community is medium to high income earners when compared to the average Nigerian community.

$E$. coli is the most common bacteria isolated from the 
tested individuals with frequency of occurrence at $40 \%$, followed by Pseudomonas spp (26.7\%), Staphylococcus aureus (13.3\%), Klebsiella spp. (13.3\%), Streptococcus spp. (6.7\%); this result agrees with other reports that indicate that $E$. coli is the commonest pathogen isolated in patients with UTI [25-28].

Results from the present study showing the prevalence of Schistosomiasis at $25 \%$ as opposed to $5 \%$ recorded for Trichonomiasis is consistent with earlier reports that $S$. haematobium is endemic throughout Nigeria. The prevalence of S. haematobium observed on Redemption Camp is comparable to $24.0 \%$ reported in Ajara community of Badagry, Lagos State, Nigeria [31] and the $36.8 \%$ average prevalence rate for Kano State, Nigeria [32]. Higher prevalence of infection has been reported elsewhere, for example, [33] reported a $S$. haematobium prevalence of $57.7 \%$ at Ibadan while [8] reported a prevalence of $69.0 \%$ for Ekiti South West Local Government of Nigeria (69.0\%). The relatively lower prevalence rate of $S$. haematobium infection recorded on Redemption Camp further confirms the suggestion that differences in socioeconomic background in terms of provision of potable water in the individual communities account for differences in prevalence rates [34]. High prevalence of $S$. haematobium has been linked to high exposure to stream water in communities where the scarcity of potable water is widespread [11].

In this study, the prevalence of bacteriuria in females is more than in males, this is in agreement with other reports which stress that bacteriuria is more frequent in females than in males during youth and adulthood [27], [28]. The fact that males examined in this study showed higher prevalence of Schistosomiasis than females is consistent with reports by [11] that unbridled contact with stream water through play in males, coupled with the fact that young males do not participate any less in water-related household chores such as fetching and cooking may account for the higher prevalence of Schistosomiasis in young adult males compared with their female counterparts.

All of the organisms encountered during the course of this study were resistant to amoxycillin, augumentin, cotrimoxazole and tetracycline. Escherichia coli in particular showed a high level of resistances to amoxicillin. Similar results have been reported by other workers such as $[21,35]$ where antibiotic resistance has been attributed to high prescription rates of these antibiotics since they are relatively cheaper and more easily available. In addition, widespread inappropriate use of antimicrobial agents in Nigeria is also due to the possibility of buying antibiotics from pharmacy stores with or without prescription; this is a significant contributing factor to the development of resistance to antimicrobial agents [36].

Three antibiotics, gentamycin, ofloxacin and notrofu- rantoin were found to be most effective for all the gram negative organisms isolated in this study particularly Pseudomonas spp., Klebsiella spp., and E. coli, while chloraphenicol was found to be effective for the gram positive organisms. Similar antibiotic susceptibility pattern have been reported elsewhere [21,37]. This result presents a glimmer of hope that if detected, treatment options by means of antibiotics are yet available. The higher costs of these antibiotics have probably limited their prescription, procurement and misuse. While the exorbitant price of these antibiotics is a blessing in disguise, it is hoped that these results will guide doctors in this locality on effective antibiotic prescription management.

The present results underscore the need for improvement in basic infrastructures such as supply of potable water in rural communities. Periodic epidemiological studies such as the one being reported here will also help in identifying the important UTI pathogens with a view to developing an effective and proper treatment model. Moreover, infection from UTI-causing pathogens can be drastically reduced when intermediate hosts of UTIcausing parasites are eradicated and by improved personal hygiene.

\section{REFERENCES}

[1] C. M. Kunin, "Urinary Tract Infections in Females," Clinical Infectious Diseases, Vol. 18, No. 1, 1994, pp. 1-10. http://dx.doi.org/10.1093/clinids/18.1.1

[2] D. H. Tambekar, S. R. Gulhane, V. K. Khandelwal and M. N. Dudhane, "Antibacterial Susceptibility of Some Urinary Tract Pathogens to Commonly Used Antibiotics," African Journal of Biotechnology, Vol. 5, No. 17, 2006, pp. 1562-1565.

[3] W. E. Stamm, "The Epidemiology of Urinary Tract Infections: Risk Factors Reconsidered," Interscience Conference on Antimicrobial Agents and Chemotherapy, Vol. 39, 1999, p. 769.

[4] J. B. Wyngaarden, L. H. Smith and J. C. Bennett, "Hospital Acquired Infections," In: Cecil Text-book of Medicine, 19th Edition, W.B. Saunders, Philadelphia, 1992.

[5] E. L. Nicolle, S. Bradley, C. Richard, C. R. James, S. M. Anthony and N. Thomas, "Infectious Disease Society of America," Guidelines for the Diagnosis and Treatment of Asymptomatic Bacteriuria in Adults, 2005, pp. 643-654.

[6] A. O. Oyagade, S. I. Smith and O. Famurewa, “Asymptomatic Significant Bacteriuria among Pregnant Women in Ado-Ekiti, Ekiti State, Nigeria," African Journal of Clinical \& Experimental Microbiology, Vol. 5, No. 1, 2004, pp. 64-77.

[7] D. A. Schwartz, "Carcinoma of the Uterine Cervix and Schistosomiasis in West Africa," Gynecologic Oncology, Vol. 19, No. 3, 1984, pp. 365-368.

[8] O. Ariyo, L. K. Olofintoye, R. A. Adeleke and O. Famurewa, "Epidemiological Study of Urinary Schisto- 
somiasis among Primary School Pupils in Ekiti State, Nigeria,” African Journal of Clinical \& Experimental Microbiology, Vol. 5, No. 1, 2004, pp. 20-29.

[9] K. Gupta, D. F. Sahm and D. Mayfield, “Antimicrobial Resistance among Uropathogens That Cause Community-Acquired Urinary Tract Infections in Women: A Nationwide Analysis," Clinical Infectious Diseases, Vol. 33, No. 1, 2001, pp. 89-94. http://dx.doi.org/10.1086/320880

[10] A. R. Manges, H. Tabor and P. Tellis, "Endemic and Epidemic Lineages of Escherichia coli That Causes Urinary Tract Infections,” Emerging Infectious Diseases, Vol. 14, No. 10, 2008, pp. 1575-1583. http://dx.doi.org/10.3201/eid1410.080102

[11] O. A. Adeyeba and S. G. T. Ojeaga, "Urinary Schistosomiasis and Concomitant Urinary Tract Pathogens among School Children in Metropolitan Ibadan, Nigeria,” African Journal of Biomedical Research, Vol. 5, 2002, pp. 103-107.

[12] E. L. Nicolle, "Asymptomatic Bacteriuria When to Screen and When to Treat," Infectious Diseases Clinical North America, Vol. 17, 2003, pp. 367-394.

[13] G. K. M. Harding, G. Z. Godfry and L. E. Nicolle, “Antimicrobial Treatment in Diabetic Women with Asymptomatic Bacteriuria,” The New England Journal of Medicine. Vol. 347, 2004, pp. 1576-1583. http://dx.doi.org/10.1056/NEJMoa021042

[14] P. Akerele, F. Abhuliren and J. Okonofua, "Prevalence of Asymptomatic Bacteriuria among Pregnant Women in Benin City, Nigeria,” Journal of Obstetrics \& Gynaecology, Vol. 21, 2001, pp. 141-144. http://dx.doi.org/10.1080/01443610020026038

[15] C. A. Ekwunife, V. O. Agbor, A. N. Ozumba, C. I. Eneanya and C. N. Ukaga, "Prevalence of Urinary Schistosomiasis in Lyede-Ame Community and in Ndokwa East Local Government Area Delta State," Nigerian Journal of Parasitology, Vol. 30, 2009, pp. 27-31.

[16] M. Cheesbrough, "District Laboratory Practice in Tropical Countries,” 2nd Edition, Cambridge University Press, Cambridge, 2007.

[17] E. L. Nicolle, "Screening for Asymptomatic Bacteriuria in Pregnancy. Canadian Guide on Preventive Health Care-Ottawa, Canada," Ottawa Health, Vol. 1, 1994, pp. 100-106.

[18] S. Gabre-Selassie, “Asymptomatic Bacteriuria in Pregnancy; Epidemiological Clinical and Microbiological Approach,” Ethiopian Medical Journal, Vol. 36, 1998, pp. 185-192.

[19] O. Olusanya, A. Ogunledun and T. A. Fakoya, “Asymptomatic Significant Bacteriuria among Pregnant and Non-Pregnant Women in Sagamu, Nigeria,” WAJM, Vol. 12, 1993, pp. 27-33.

[20] P. Ho, T. Que, S. S. Chiu, R. W. H. Yung, T. Ng and D. N. C. Tsung, "Fluoroquinolone and Other Antimicrobial Resistance in Invasive Pneumococci, Hong Kong," Emerging Infectious Diseases, Vol. 10, No. 7, 2004, pp. 12501257.http://dx.doi.org/10.3201/eid1007.030612

[21] R. M. Mordy and P. O. Erah, "Susceptibility of Common Urinary Isolates to the Commonly Used Antibiotics in a
Tertiary Hospital in southern Nigeria,” African Journal of Biotechnology, Vol. 5, 2006, pp. 1067-1071.

[22] A. Raufu, "Influx of Fake Drugs to Nigeria Worries Health Experts,” BMJ, Vol. 324, 2002, p. 698. http://dx.doi.org/10.1136/bmj.324.7339.698

[23] S. T. Cowan, "Cowan and Steele's Manual for the Identification of Medical Bacteria London,” 3rd Ed, Cambridge University Press, Cambridge, 1993.

[24] F. C. Tenover, "Performance Standards for Antimicrobial Disc Susceptibility Test Approved Standard, M2-A5 Pub,” National Committee for Clinical Laboratory Standards, Villanova Pan, USA, 1993.

[25] K. O. Akinyemi, S. A. Alabi, M. A. Taiwo and E. A. Omonigbehin, "Antimicrobial Susceptibility Pattern and Plasmid Profiles of Pathogenic Bacteria Isolated from Subjects with Urinary Tract Infections in Lagos, Nigeria," Nigerian Quarterly Journal of Hospital Medicine, Vol. 1, 1997, pp. 7-11.

[26] M. Ebie, Y. T. Kandaki-Olukemi, J. Ayanbadejo and K. B. Tanyigna, "UTI Infections in a Nigerian Military Hospital,” Nigerian Journal of Microbiology, Vol. 15, No. 1, 2001, pp. 31-37.

[27] A .S. Kolawole, O. M. Kolawole, Y. T. Kandaki-Olukemi and S. K. Babatunde, "Prevalence of Urinary Tract Infections (UTI) among Patients Attending Dalhatu Araf Specialist Hospital, Lafia, Nasarawa State, Nigeria,” International Journal of Medicine and Medical Sciences, Vol. 1, No. 5, 2009, pp. 163-167.

[28] T. I. Mbata, "Prevalence and Antibiogram of UTIs among Prisons Inmates in Nigeria,” International Journal of Microbiology, Vol. 3, No. 2, 2007, pp. 11-15.

[29] V. T. Andriole, “The Role of Tamm-Horsfall Protem in the Pathogenesis of Reflux Nephropathy and Chronic Pyelonephritis," Yale Journal of Biology and Medicine, Vol. 58, 1985, pp. 91-100.

[30] K. A. Burbige, A. B. Retic, A. Colony, S. B. Bauer and R. Lebowitz, "UTI in Boys,” Journal of Urology, Vol. 132, 1984, pp. 541-542.

[31] G. C. Ezejie and M. A. Ade-Serrano, "Schistosoma Haematobium in Ajara Community Badagry, Nigeria. A Study on Prevalence, Intensity and Morbidity from Infection among Primary School Children,” Tropical and Geographical Medicine, Vol. 33, 1981, pp. 175-180.

[32] C. Betterton, G. T. Ndifon, S. E. Bassey, R .M. Tom and T. Oyeyi, "Schistosomiasis in Kano State, Nigeria I. Human Infection near Dam Sites and the Distribution Habitat Preferences of Potential Snail Intermediate Hosts," Annals of Tropical Medicine and Parasitology, Vol. 82, No. 6, 1988, pp. 561-570.

[33] G. O. Adewumi, P. Furu, N. O. Christensen and F. Olorunmola, "Endemicity, Seasonality and Focality of Transmission of Human Schistosomiasis in Three Communities in South-Western Nigeria,” Tropical Medicine and Parasitology, Vol. 42, 1991, pp. 332-334.

[34] A. E. Butterworth, A. J. C. Fulford, D. W Dunne, J. H. Duma and R. Sturrock, "Longitudinal Studies on Human Schistosomiasis," Philosophical Transactions of the Royal Society, Vol. 321, No. 1207, 1988, pp. 105-118. 
[35] P. Galia, R. Erica, B. Gilad and B. Herve, "Molecular Epidemiology of Asymptomatic Bacteriuria in the Elderly,” Journal of Age and Ageing, Vol. 32, No. 6, 2003, pp. 670-673.

[36] B. A. Mincey and M. A. Parkulo, “Antibiotic Prescribing Practices in a Teaching Clinic: Comparison of Resident and Staff Physicians,” Southern Medical Journal, Vol. 94,
No. 4, 2001, pp. 365-369.

[37] N. Frank-Peterside and E. C. Wokoma, "Prevalence of Asymptomatic Bacteriuria in Students of University of Port-Harcourt Demonstration Secondary School,” Journal of Applied Sciences and Environmental Management, Vol. 13, No. 2, 2009, pp. 55-58. 